\title{
Mortality and suicide after self-harm: community cohort study in Taiwan
}

Vincent C. H. Chen, Happy K. L. Tan, Chung-Ying Chen, Tony H. H. Chen, Long-Ren Liao, Charles T. C. Lee, Michael Dewey, Robert Stewart, Martin Prince and Andrew T. A. Cheng

\section{Background}

Little is known about outcomes after self-harm in East Asia.

\author{
Aims \\ To investigate mortality after self-harm in a Taiwanese \\ population.
}

\section{Method}

Between 2000 and 2003, 1083 individuals who self-harmed were identified through a population self-harm register in Nantou County, Taiwan, and followed until 2007 for date and cause of death on a national mortality database.

\section{Results}

In total, 145 individuals died, 48 through suicide. The risks of all-cause and suicide mortality in the first year were $4.7 \%$ and $2.1 \%$ respectively, representing 8 - and 131 -fold age- and gender-standardised increases. Male gender and older age were independent risk factors for both suicide and nonsuicide mortality. Use of more lethal methods in the index episode was associated with higher mortality but this was accounted for by gender.

\section{Conclusions}

Results in this sample support the recommendation that people with a history of recent self-harm should be a major target for suicide prevention programmes.

\section{Declaration of interest}

None.
Previous self-harm is an important risk factor for suicide, occurring in $40-60 \%$ of instances. ${ }^{2-5}$ One systematic review found that those who harmed themselves had a $0.5-2 \%$ risk of suicide within 1 year of the index self-harm act, and a suicide risk in excess of $5 \%$ after 9 years. ${ }^{6}$ Long-term follow-up studies have found that the increased risk of suicide persists. ${ }^{7}$ The risk of suicide is $30-100$ times higher within the first year following the self-harm episode than in the general population. ${ }^{3,8-9}$ Other studies have suggested that those who self-harm also have higher mortality from other causes. ${ }^{10}$

Male gender and older age have been suggested as predictors of suicide after self-harm, ${ }^{3}$ although not all studies have found a gender difference. ${ }^{10}$ Other demographic factors and index selfharm methods have received less attention as predictors. ${ }^{11}$ Few previous studies have investigated risk factors for both suicide and all causes of death in a systematic and representative sample of people who self-harm. ${ }^{12}$ Methodological problems cited in one systematic review include small and highly selected samples, weak methods for detecting suicide during follow-up and flawed analysis. ${ }^{6}$ Another limitation is that nearly all reports about this topic have come from Europe, North America and Australasia, with little research from Asia.

In Taiwan, suicide rates have increased more than threefold during the past 10 years, and suicide has been the ninth leading cause of death since 1999. The relationship between self-harm and suicide is important for planning interventions to reduce suicide rates. ${ }^{6}$ In this study, we aimed to assess rates of mortality after self-harm from suicide and other causes in Taiwan through a prospective community-based cohort study. A further objective was to investigate demographic factors and potential lethality of the self-harm as predictors for later mortality.

\section{Method}

\section{Study sample}

The analysed sample were individuals with an episode of selfharm consecutively recruited from a suicide and self-harm register system in Nantou County from July 2000 to March 2003. Nantou County is located in central Taiwan, with a total population of approximately 500000 . The county is close to the centre of a major earthquake that took place on 21 September 1999, and a community mental health centre was established in this county to provide mental healthcare for survivors from the earthquake disaster, supported by a specific reconstruction fund from the government. The centre was staffed with ten mental health nurses, five psychologists and five social workers, and was actively supervised by two senior psychiatrists. In collaboration with the local health authority, this centre established a new reporting system in June 2000 to identify all inhabitants who carried out an act of suicide/self-harm. This was the first population register in Taiwan to systematically collect data on both suicide and self-harm, and has been described previously. ${ }^{13,14}$

\section{Definition of self-harm}

Self-harm was defined as all acts of self-poisoning or self-injury, irrespective of the degree of suicidal intent. ${ }^{15}$ Other terms in common use, namely attempted suicide and parasuicide, are subsumed within this definition. ${ }^{16}$ In this study, in practice, any episodes of self-harm resulting in medical attention referred by a variety of community resources as detailed below were included.

\section{Data collection}

A structured data coding form was designed to ensure the quality of the registration system. This form contained sociodemographic information (age, gender, education, marital status, location of residency) and information regarding the suicide/self-harm act (date of the self-harm and method(s) used), and the nature of the referral source(s). A detailed description of the self-harm method included the name of any drugs or chemicals used. This form was completed, for all people who carried out an act of suicide/self-harm, by a group of informants working in all agencies and settings where cases were routinely identified. They included doctors and nurses in the health sector (general hospital 
emergency room, general practice and local public health centres), and workers in other public and private sectors (firefighters, police officers, social workers and non-governmental organisation workers). A training course was conducted for all potential informants on the use of the form before the inception of the register in 2000. A meeting was held every 3 months with leaders of all referral sources to review the operation of the reporting system. Nantou Health Bureau officers monitored the health sector regularly. All completed forms were forwarded to the community mental health centre within 24 hours. Staff at the centre checked the forms to identify any missing or unclear information, which was then completed during regular weekly visits to the agencies/settings through further questioning of informants. The study received ethical approval from the Tasotun Psychiatric Center Research Ethics Committee. Each person's first self-harm act during the study period was treated as the index episode. Follow-up was then carried out between July 2000 and December 2007.

\section{Identification of suicide}

Information regarding personal identification of all individuals (national identifier number, name, gender, location of residency and date of birth) recruited during the study period were checked against the databases of the national death register system, in which all deaths from unnatural causes (suicide, accidental death and homicide) are decided on by a death verdict jointly assigned by a prosecutor and a coroner, whose main concern is the possibility of homicide. Since a suicide verdict is important in this decision, a thorough enquiry is usually made about suicide intentions. In a previous psychological autopsy study in Taiwan, only 2 out of 117 suicides were misclassified by coroners and prosecutors as accidental deaths. ${ }^{17}$

\section{Risk and standardised mortality ratios for suicide, other causes and all causes}

The risk of suicide, death by other causes, and total mortality (which included all unnatural deaths and deaths by natural causes) were calculated in terms of the number at risk: that is, the number of individuals that entered the respective interval alive minus half of the number of those lost or censored in the respective interval. Each person's first presentation within the study period was used in the calculation of risk over time. Using indirect standardisation, annual age- and gender-specific mortality rates from suicide, non-suicide causes and all causes from Taiwanese national mortality statistics for the period from 2001 to 2003 were applied to the study sample to compute expected numbers of deaths. The standardised mortality ratio (SMR) within 1 year of self-harm in the study sample was calculated as a ratio of actual versus expected numbers of deaths.

\section{Statistical analysis}

Each person's first presentation within the study period was used in the calculation of risk over time. All individuals traced until December 2007 by the national death register system for any length of time from their first presentation were entered into a survival analysis. The risk of suicide, of mortality excluding suicide and total mortality during the follow-up period was calculated using survival curves. We calculated annual mortality rates for each of the 7 years following the index episode of selfharm, as well as cumulative mortality rates for the first 5 years since the self-harm episode. In the survival analysis, the time function was calculated as the number of months from the index episode of self-harm to December 2007 (end of follow-up) for those who survived until then, or until the date of death if this preceded the end of the follow-up interval. Cox regression models were fitted to estimate the effects of gender, age, education and marital status as well as potential lethality of method used in the index episode. We categorised the suicide methods as high lethality (fatality proportion $>26 \%$ ) and low lethality (fatality proportion <4\%) groups, as previously reported. ${ }^{14}$ The high lethality group consisted of pesticide, gas, hanging and other violent methods, whereas the low lethality group included drug ingestion and self-cutting. Hazard ratios with $95 \%$ confidence intervals were calculated. Analyses were carried out using the Statistical Package for the Social Sciences version 13.0 for Windows and STATA version 9.0 for Windows.

\section{Results}

\section{Sample characteristics}

A total of 1083 cases of self-harm were registered between July 2000 and March 2003. Of these, 1080 (99.7\%) could be traced. Until December 2007, follow-up information was available for all individuals with a mean follow-up time of 5.8 years (s.d. $=1.7$, range 1 day to 7.6 years). The sample consisted of $392(36.3 \%)$ men and $688(63.7 \%)$ women. The mean age was 37.1 years $($ s.d.=15.9), ranging from 11 to $90 ; 67.8 \%$ had fewer than 9 years of education; nearly $90 \%$ were living in the Nantou area; over half of the individuals were married (52.2\%), with $27.9 \%$ single, $13.9 \%$ divorced and $5.5 \%$ widowed. The methods of self-harm included drug overdose $(n=472,43.7 \%)$, self-cutting ( $n=253,23.4 \%)$, pesticide poisoning $(n=255,23.6 \%)$ and other violent methods such as jumping from a high place or drowning $(n=48,4.4 \%)$, gas inhalation $(n=32,3.0 \%)$ and hanging $(n=13,1.2 \%)$ (Table 1$)$.

\begin{tabular}{|c|c|}
\hline Characteristics & Self-harm, ${ }^{a} n(\%)$ \\
\hline \multicolumn{2}{|l|}{ Gender } \\
\hline Female & $688(63.7)$ \\
\hline Male & $392(36.3)$ \\
\hline \multicolumn{2}{|l|}{ Age, years } \\
\hline$<25$ & 273 (25.3) \\
\hline $25-44$ & $526(48.7)$ \\
\hline $45-64$ & $196(18.1)$ \\
\hline$\geqslant 65$ & $85(7.9)$ \\
\hline \multicolumn{2}{|l|}{ Residence } \\
\hline Other area & 110 (10.2) \\
\hline Suburban & $624(57.8)$ \\
\hline Rural & $346(32.0)$ \\
\hline \multicolumn{2}{|l|}{ Education } \\
\hline$>9$ years & 327 (30.3) \\
\hline$\leqslant 9$ years & 732 (67.8) \\
\hline Missing & $21(1.9)$ \\
\hline \multicolumn{2}{|l|}{ Marital status } \\
\hline Single & 301 (27.9) \\
\hline Married & $564(52.2)$ \\
\hline Divorced & $150(13.9)$ \\
\hline Widowed & $59(5.5)$ \\
\hline Missing & $6(0.6)$ \\
\hline \multicolumn{2}{|l|}{ Method } \\
\hline Drug overdose & 472 (43.7) \\
\hline Self-cutting & $253(23.4)$ \\
\hline Pesticide poisoning & $255(23.6)$ \\
\hline Other violent & $48(4.4)$ \\
\hline Gas inhalation & $32(3.0)$ \\
\hline Hanging & $13(1.2)$ \\
\hline Missing & $7(0.6)$ \\
\hline
\end{tabular}




\section{Risk of suicide following self-harm}

By the end of the follow-up period, 48 (4.4\%) individuals had completed suicide: 31 men $(2.9 \%)$ and 17 women (1.6\%). More suicides $(n=22,45.8 \%)$ occurred during the first year after the self-harm index episode than in any other year. The cumulative risk by 1 year was $2.1 \%$, by 2 years $2.8 \%$ and by 5 years $3.8 \%$. The risk continued to accumulate but the amplitude was highest within the first year (Table 2). In unadjusted Cox regression

\begin{tabular}{|c|c|c|c|}
\hline Timing of death & $\begin{array}{l}\text { Exposed } \\
\text { to risk, } n\end{array}$ & $\begin{array}{l}\text { Number } \\
\text { of deaths }\end{array}$ & $\begin{array}{l}\text { Risk, \% } \\
(95 \% \mathrm{Cl})\end{array}$ \\
\hline \multicolumn{4}{|l|}{ Suicides } \\
\hline 0-1 year & 1065.5 & 22 & $2.1(1.2-2.9)$ \\
\hline $1-2$ years & 1021 & 8 & $0.8(0.2-1.3)$ \\
\hline $2-3$ years & 995.5 & 2 & $0.2(0.0-0.5)$ \\
\hline $3-4$ years & 979 & 3 & $0.3(0.0-0.7)$ \\
\hline $4-5$ years & 944 & 4 & $0.4(0.0-0.8)$ \\
\hline $5-6$ years & 758.5 & 8 & $1.1(0.3-1.8)$ \\
\hline $6-7$ years & 397 & 1 & $0.3(0.0-0.7)$ \\
\hline \multicolumn{4}{|c|}{ Non-suicide deaths } \\
\hline 0-1 year & 1069 & 29 & $2.7(1.7-3.7)$ \\
\hline $1-2$ years & 1025 & 16 & $1.6(0.8-2.3)$ \\
\hline $2-3$ years & 1004 & 19 & $1.9(1.0-2.7)$ \\
\hline 3-4 years & 982.5 & 10 & $1.0(0.4-1.6)$ \\
\hline $4-5$ years & 945.5 & 7 & $0.7(0.2-1.3)$ \\
\hline $5-6$ years & 759 & 9 & $1.2(0.4-2.0)$ \\
\hline 6-7 years & 399 & 5 & $1.3(0.2-2.3)$ \\
\hline \multicolumn{4}{|c|}{ Death from any causes } \\
\hline 0-1 year & 1080 & 51 & $4.7(0.2-2.3)$ \\
\hline $1-2$ years & 1029 & 24 & $2.3(1.4-3.3)$ \\
\hline $2-3$ years & 1005 & 21 & $2.1(1.2-3.0)$ \\
\hline 3-4 years & 984 & 13 & $1.3(0.6-2.0)$ \\
\hline $4-5$ years & 947.5 & 11 & $1.2(0.5-1.8)$ \\
\hline $5-6$ years & 763 & 17 & $2.2(1.2-3.3)$ \\
\hline 6-7 years & 399.5 & 6 & $1.5(0.3-2.7)$ \\
\hline
\end{tabular}

analyses, risk factors for suicide mortality were found to be male gender, an older age and higher lethality of method used in the index self-harm act. Men had nearly a 3.5-fold higher suicide mortality compared with women and those aged above 64 had 5.9 times higher suicide mortality than those aged 10-24 years. After adjusting for gender, there was no significant difference in the association between self-harm method and risk of suicide. The final independent predictors were male gender and increased age in the adjusted model (Table 3 ).

\section{Risk of general and non-suicide mortality following self-harm}

Of the 1080 individuals who self-harmed, a total of 145 (13.4\%) died during the follow-up period, 97 of whom died from causes other than suicide $(9.0 \%)$. The risk by 1 year was $2.7 \%, 2$ years $4.2 \%$ and 5 years $7.8 \%$ for non-suicide causes and was $4.7 \%$, $6.9 \%$ and $11.4 \%$ respectively for all-cause mortality (Table 2 ). The frequency was also highest within the first year for both of these outcomes (Table 2). In the unadjusted Cox regression model, risk factors for death from any cause and non-suicide mortality were male gender, increased age, lower education, widowed status, and use of self-harm methods that had high lethality. In the adjusted model, only male gender and older age were independent predictors of both outcomes (Tables 4 and 5).

\section{SMR in the first year following self-harm}

Age and gender SMRs were applied to compare self-harm case outcomes with those of the general population. Standardised mortality ratios were described as simple ratios rather than according to the convention of $100=$ no difference, because of the large size of the effects. Compared with the annual expected numbers of suicide deaths derived from general population data in Nantou County and in Taiwan, individuals who self-harmed had an 87 -fold and a 131-fold respective risk of suicide within

\begin{tabular}{|c|c|c|c|c|c|}
\hline \multirow[b]{2}{*}{ Variable } & \multirow[b]{2}{*}{ Deaths from suicide, ${ }^{a} n / N(\%)$} & \multicolumn{2}{|c|}{ Unadjusted hazard ratio } & \multicolumn{2}{|c|}{ Adjusted hazard ratio } \\
\hline & & Estimate $(95 \% \mathrm{Cl})$ & $P$ & Estimate $(95 \% \mathrm{Cl})$ & $P$ \\
\hline \multicolumn{6}{|l|}{ Gender } \\
\hline Female & $17 / 688(2.5)$ & 1.00 & & & 1.00 \\
\hline Male & $31 / 392(7.9)$ & $3.46(1.92-6.26)$ & $<0.001$ & $2.47(1.28-4.75)$ & 0.007 \\
\hline \multicolumn{6}{|l|}{ Age, years } \\
\hline $10-24$ & 5/273 (1.8) & 1.00 & & & 1.00 \\
\hline $25-44$ & $25 / 526(4.8)$ & $2.66(1.02-6.95)$ & 0.046 & $3.24(1.14-9.23)$ & 0.028 \\
\hline $45-64$ & 11/196 (5.6) & $3.34(1.16-9.62)$ & 0.025 & $4.32(1.22-15.32)$ & 0.023 \\
\hline$\geqslant 65$ & $7 / 85(8.2)$ & $5.87(1.86-18.53)$ & 0.003 & $8.00(1.95-32.88)$ & 0.004 \\
\hline \multicolumn{6}{|l|}{ Residence } \\
\hline Rural & $17 / 346(4.9)$ & 1.00 & & 1.00 & \\
\hline Suburban & $28 / 624(4.5)$ & $0.91(0.50-1.65)$ & 0.746 & $0.88(0.48-1.63)$ & 0.694 \\
\hline Other area & $3 / 110(2.7)$ & $0.55(0.16-1.88)$ & 0.342 & $0.58(0.17-1.99)$ & 0.384 \\
\hline \multicolumn{6}{|l|}{ Education } \\
\hline$>9$ years & $16 / 327(4.9)$ & 1.00 & & 1.00 & \\
\hline$\leqslant 9$ years & $32 / 732(4.4)$ & $0.94(0.52-1.72)$ & 0.844 & $0.74(0.39-1.41)$ & 0.363 \\
\hline \multicolumn{6}{|l|}{ Marital status } \\
\hline Single & $14 / 301(4.7)$ & 1.00 & & 1.00 & \\
\hline Married & $22 / 564$ (3.9) & $0.85(0.43-1.65)$ & 0.624 & $0.49(0.22-1.11)$ & 0.086 \\
\hline Divorced & $9 / 150(6.0)$ & $1.30(0.56-3.00)$ & 0.542 & $0.93(0.37-2.33)$ & 0.871 \\
\hline Widowed & $3 / 59(5.1)$ & $1.23(0.35-4.28)$ & 0.746 & $0.50(0.12-2.14)$ & 0.348 \\
\hline \multicolumn{6}{|l|}{ Method } \\
\hline Low fatality & 25/725 (3.4) & 1.00 & & 1.00 & \\
\hline High fatality ${ }^{c}$ & $23 / 348(6.6)$ & $2.05(1.16-3.60)$ & 0.013 & $1.33(0.72-2.46)$ & 0.358 \\
\hline
\end{tabular}




\begin{tabular}{|c|c|c|c|c|c|}
\hline \multirow[b]{2}{*}{ Variable } & \multirow{2}{*}{ 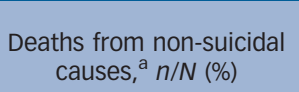 } & \multicolumn{2}{|c|}{ Unadjusted hazard ratio } & \multicolumn{2}{|c|}{ Adjusted hazard ratio } \\
\hline & & Estimate $(95 \% \mathrm{Cl})$ & $P$ & Estimate $(95 \% \mathrm{Cl})$ & $P$ \\
\hline \multicolumn{6}{|l|}{ Gender } \\
\hline Female & 36/688 (5.2) & 1.00 & & 1.00 & \\
\hline Male & $61 / 392(15.6)$ & $3.28(2.18-4.96)$ & $<0.001$ & $2.48(1.59-3.87)$ & $<0.001$ \\
\hline \multicolumn{6}{|l|}{ Age, years } \\
\hline 10-24 & 7/273 (2.6) & 1.00 & & & 1.00 \\
\hline $25-44$ & $25 / 526(4.8)$ & $1.92(0.83-4.44)$ & 0.127 & $2.06(0.77-5.56)$ & 0.152 \\
\hline $45-64$ & 27/196 (13.8) & $6.05(2.63-13.89)$ & $<0.001$ & $5.25(1.79-15.45)$ & 0.003 \\
\hline$\geqslant 65$ & $38 / 85(44.7)$ & $24.86(11.09-55.72)$ & $<0.001$ & $18.76(6.22-56.55)$ & $<0.001$ \\
\hline \multicolumn{6}{|l|}{ Residence } \\
\hline Rural & $35 / 346(10.1)$ & 1.00 & & 1.00 & \\
\hline Suburban & $52 / 624(8.3)$ & $0.81(0.53-1.25)$ & 0.341 & $0.80(0.51-1.24)$ & 0.317 \\
\hline Other area & $10 / 110(9.1)$ & $0.89(0.44-1.80)$ & 0.745 & $1.02(0.50-2.07)$ & 0.966 \\
\hline \multicolumn{6}{|l|}{ Education } \\
\hline$>9$ years & 12/327 (3.7) & 1.00 & & 1.00 & \\
\hline$<9$ years & $84 / 732(11.5)$ & $3.33(1.82-6.10)$ & $<0.001$ & $1.77(0.94-3.35)$ & 0.077 \\
\hline \multicolumn{6}{|l|}{ Marital status } \\
\hline Single & 13/301 (4.3) & 1.00 & & 1.00 & \\
\hline Married & $56 / 564(9.9)$ & $2.34(1.28-4.28)$ & 0.006 & $0.88(0.40-1.93)$ & 0.747 \\
\hline Divorced & $12 / 150(8.0)$ & $1.89(0.86-4.14)$ & 0.113 & $1.25(0.51-3.06)$ & 0.622 \\
\hline Widowed & $16 / 59(27.1)$ & $7.34(3.53-15.27)$ & $<0.001$ & $1.26(0.48-3.31)$ & 0.635 \\
\hline \multicolumn{6}{|l|}{ Method } \\
\hline Low fatality & 48/725 (6.6) & 1.00 & & 1.00 & \\
\hline High fatalityc & 49/348 (14.1) & $2.30(1.55-3.43)$ & $<0.001$ & $1.04(0.68-1.59)$ & 0.852 \\
\hline
\end{tabular}

\begin{tabular}{|c|c|c|c|c|c|}
\hline \multirow[b]{2}{*}{ Variable } & \multirow[b]{2}{*}{ Deaths from all causes, ${ }^{a} n / N(\%)$} & \multicolumn{2}{|c|}{ Unadjusted hazard ratio } & \multicolumn{2}{|c|}{ Adjusted hazard ratio } \\
\hline & & Estimate $(95 \% \mathrm{Cl})$ & $P$ & Estimate $(95 \% \mathrm{Cl})$ & $P$ \\
\hline \multicolumn{6}{|l|}{ Gender } \\
\hline Female & $53 / 688(7.7)$ & 1.00 & & 1.00 & \\
\hline Male & 92/392 (23.5) & $3.34(2.38-4.69)$ & $<0.001$ & $2.47(1.71-3.56)$ & $<0.001$ \\
\hline \multicolumn{6}{|l|}{ Age, years } \\
\hline $10-24$ & 12/273 (4.4) & 1.00 & & 1.00 & \\
\hline $25-44$ & $50 / 526(9.5)$ & $2.23(1.19-4.19)$ & 0.012 & $2.60(1.27-5.33)$ & 0.009 \\
\hline $45-64$ & 38/196 (19.4) & $4.92(2.57-9.41)$ & $<0.001$ & $5.20(2.31-11.69)$ & $<0.001$ \\
\hline$\geqslant 65$ & $45 / 85(52.9)$ & $16.69(8.82-31.57)$ & $<0.001$ & $16.25(7.02-37.64)$ & $<0.001$ \\
\hline \multicolumn{6}{|l|}{ Residence } \\
\hline Rural & 52/346 (15.0) & 1.00 & & 1.00 & \\
\hline Suburban & 80/624 (12.8) & $0.84(0.59-1.20)$ & 0.336 & $0.83(0.58-1.18)$ & 0.299 \\
\hline Other area & 13/110 (11.8) & $0.78(0.42-1.43)$ & 0.422 & $0.86(0.47-1.60)$ & 0.642 \\
\hline \multicolumn{6}{|l|}{ Education } \\
\hline$>9$ years & 28/327 (8.6) & 1.00 & & 1.00 & \\
\hline$\leqslant 9$ years & 116/732 (15.8) & $1.96(1.30-2.97)$ & 0.001 & $1.19(0.77-1.85)$ & 0.436 \\
\hline \multicolumn{6}{|l|}{ Marital status } \\
\hline Single & 27/303 (9.0) & 1.00 & & 1.00 & \\
\hline Married & 78/56 (13.8) & $1.57(1.01-2.43)$ & 0.045 & $0.67(0.38-1.16)$ & 0.151 \\
\hline Divorced & 21/150 (14.0) & $1.58(0.90-2.80)$ & 0.114 & $1.05(0.56-1.99)$ & 0.878 \\
\hline Widowed & 19/59 (32.2) & $4.14(2.30-7.45)$ & $<0.001$ & $0.89(0.42-1.88)$ & 0.761 \\
\hline \multicolumn{6}{|l|}{ Method } \\
\hline Low fatality ${ }^{\mathrm{b}}$ & 73/725 (10.1) & 1.00 & & 1.00 & \\
\hline High fatality ${ }^{c}$ & 72/348 (20.7) & $2.21(1.60-3.07)$ & $<0.001$ & $1.13(0.80-1.61)$ & 0.491 \\
\hline
\end{tabular}

the first year after the index self-harm act. The respective SMRs for non-suicide death were 4.3 and 4.7, and for all causes were 7.3 and 8.1. Similar SMRs were observed for non-suicide mortality between men and women, whereas suicide SMRs were twice as strong in men compared with women. The higher SMR for suicide and non-suicide death also existed for 4-year cumulative risk. Individuals who self-harmed had a 35 -fold and a 52-fold cumulative risk of suicide within 4 years after the index self-harm act compared with the risks of the general populations in Nantou County and Taiwan respectively. 


\section{Discussion}

To our knowledge, this is the first epidemiological study to investigate mortality following self-harm in a defined community population in Asia. The main findings were that the risk of suicide in the subsequent year was $2.1 \%$ (95\% CI 1.2-2.9) representing an approximately 131-fold age and gender standardised increase compared with the general population in Taiwan. The risk of all-cause mortality in the first year was $4.7 \%$ (95\% CI 3.5-6.0): approximately eight times the risk in the general population. Male gender and older age were independent risk factors for both suicide and non-suicide mortality. Use of more lethal methods in the index self-harm episode was associated with subsequent mortality before adjustment but this association was confounded by gender.

\section{Strengths and limitations}

Through the cooperation of many different agencies, including local government, public health, social services, firefighters as well as police and medical services, the present study has several strengths. First, the large sample data-set is based on a consecutive community sample of people who were registered following an act of self-harm, and is not restricted to individuals seen by mental health services or those admitted to general hospital wards or emergency rooms. Second, we used survival analysis that takes account of the variable duration of follow-up. Third, we were able to trace a high proportion of the sample, with only $0.3 \%$ untraced. Finally, besides the record at the index event, mental health centre staff and local public health nurses attempted to follow-up all cases, in order to correct missing data, resulting in a high-quality data-set and high tracing rate.

Loss to follow-up is a major methodological consideration in cohort studies, and we had three individuals that were untraceable and they were all male. Nonetheless, due to our large sample size and high tracing rate, we feel this will have had little impact on the findings. The identification of suicide mortality in Taiwan has already been demonstrated to have high validity in one previous study, which found higher than $98 \%$ accuracy. ${ }^{17}$ However, a few suicide deaths may still be missed owing to their inclusion in other categories. Compared with previous studies, some of which have chosen to define suicide as including deaths from undetermined causes and accidental poisonings as well as official suicides, ${ }^{3}$ our definition is relatively restrictive. If we adopted a definition of suicide that included deaths from undetermined causes and accidental poisonings, the number would increase to $52(4.8 \%)$, with a cumulative risk by 1 year of $2.3 \%$, by 2 years of $3.2 \%$ and by 5 years of $4.2 \%$ : slightly higher than the original results.

\section{High suicide risk after self-harm}

Our findings demonstrate an important risk of fatal repetition of self-harm in this sample, especially within the following year. The $2.1 \%$ risk in the first year is relatively high compared with corresponding figures reported in the UK ranging from 0.5 to $0.7 \%, 3,9,18$ but is very close to the finding from a systematic review with a median value of $2.0 \% .^{6}$ Heterogeneity in research of this nature may arise from different distributions of risk factors between samples and source populations, such as higher proportions of younger people with lower consequent suicide, or differences in underlying suicide rates between different countries. ${ }^{3}$ In our sample, the risk was highest in the first year and continues to accumulate. Cooper and colleagues ${ }^{9}$ also found that risk was particularly high immediately (6 months) after the index self-harm act. This has clearly important implications for suicide prevention. However, several longer follow-up studies have suggested that the risk of consequent suicide remains raised even 16-37 years later ${ }^{7,18,19}$ and have stressed the importance of long-term follow-up.

\section{Excess total and non-suicide mortality}

The present study also found higher overall and non-suicide mortality rates after self-harm, compared with the general population. These risks were also highest in the first year after self-harm and continued to accumulate. Previous studies have also found that only part of the elevated all-cause mortality rate following self-harm is explained by suicide, and that there remains an unexplained component. ${ }^{12,20}$ Some investigators have argued that the elevated non-suicide mortality may be explained by accidental deaths rather than deaths from natural causes ${ }^{10,21}$ and some of these in turn may result from misclassified suicide deaths. ${ }^{22}$ However, one study found that natural causes of death besides accidents were also higher after self-harm. ${ }^{20}$ One possible explanation lies in worse physical health caused by the method of self-harm such as damage incurred as a result of pesticide ingestion, burns, gas and other chemical substances. In unadjusted analyses, we found that the lethality of the self-harm method was associated with higher non-suicide and overall mortality. However, men and older people have been found to be more likely to choose more violent methods that will result in more negative physical consequences. In addition, older people may be more physically vulnerable to any damage incurred, even potentially from lower lethality methods such as drug overdose. Consistent with this, the association between method lethality and subsequent non-suicide mortality was reduced substantially after adjustment for age and gender. Another possibility is that individuals who self-harm have a high proportion of mental disorder such as depression, ${ }^{23}$ which itself is associated with an increased all-cause mortality risk, ${ }^{24}$ an association which is not fully explained by confounding or mediation by behavioural or lifestyle factors, and possibly implying specific biological mechanisms and/or limited healthcare access as underlying causal pathways. Related to this, mental disorder is also associated with the risk of incident physical disorders such as coronary heart disease $^{25}$ and diabetes, ${ }^{26}$ as well as with reduced treatment adherence. $^{27}$ These may all play a role in non-suicide mortality following self-harm.

\section{Age and gender}

We found that the risk of suicide following self-harm was much higher in men than in women, even after controlling for the effect of age and method used in the index episode. This finding is consistent with reports from Western countries. ${ }^{3,28,29}$ For SMRs, both within 1 year and over the full follow-up period, men were at a higher risk than women. The risk was also found to increase prominently with age at the time of the self-harm episode and those aged over 64 years had a nearly sixfold higher risk than those aged 10-24 years, which also accords with a previous report. ${ }^{3}$ This finding is consistent with the suggestion in other settings that selfharm in men and older people is associated with higher suicidal intent, even after a failed attempt. This would have obvious clinical implications regarding the need to assess and monitor intent, and develop appropriate and acceptable psychosocial and supportive interventions for those most at risk.

\section{Other factors}

Apart from male gender and increased age, other demographic factors such as education, marriage and living area had no influence on consequent suicide or other mortality in adjusted 
models. Although lethality of suicide method was associated with a higher risk of suicide in the unadjusted model, this association was confounded by gender. For non-suicide and all-cause mortality, the method of self-harm was again not associated in the final model after controlling for gender and age.

\section{Implications}

Suicide is a relative rare event that has made its prediction and prevention difficult. Results from this report, as with findings from other studies, support the view that people with a history of self-harm should be a particular focus for prevention programmes. This is particularly the case for men and older people, for whom risk-reducing interventions are most pressingly required. The higher death rate from non-suicidal causes after self-harm emphasises the importance of physical healthcare among those who self-harm, both in terms of delayed or chronic effects of the self-harm act itself, and in terms of general health promotion and disease prevention.

Vincent C. H. Chen, MD, PhD, Department of Psychiatry, Chung San Medical University Hospital and School of Medicine, Chung Shan Medical University, Taichung, Taiwan; Happy K. L. Tan, MD, Taoyuan Mental Hospital, Taoyuan, Taiwan; ChungYing Chen, MD, Department of Psychiatry, Tsao-Tun Psychiatric Center, Nantou, Taiwan; Tony H. H. Chen, MD, PhD, Institute of Preventive Medicine, College of Public Health, National Taiwan University, Taiwan; Long-Ren Liao, MHS, Health Bureau, Nantou County Government, Nanyou, Taiwan; Charles T. C. Lee, PhD, Department of Public Health, College of Health Science, Kaohsiung Medical University, Kaohsiung, Taiwan; Michael Dewey, PhD, Robert Stewart, MD, PhD, Martin Prince, MD, King's College London, Institute of Psychiatry, London, UK; Andrew T. A. Cheng, MD, DSC (London), FRCPsych, Institute of Biomedical Sciences, Academia Sinica, Taipei, Taiwan

Correspondence: Andrew Cheng, MD, PhD, Institute of Biomedical Sciences, Academia Sinica, Taipei, Taiwan, 11529. Email: bmandrew@gate.sinica.edu.tw

First received 5 Apr 2010, final revision 20 Jul 2010, accepted 28 Sep 2010

\section{Funding}

R.S. is funded by the NIHR Specialist Biomedical Research Centre for Mental Health at the South London and Maudsley NHS Foundation Trust and Institute of Psychiatry, King's college London.

\section{Acknowledgements}

The authors thank the staffs of Nantou Mental Health Center for their excellent work in data collection.

\section{References}

1 Sakinofsky I. Repetition of suicidal behaviour. In The International Handbook of Suicide and Attempted Suicide (eds K Hawton, $\mathrm{K}$ van Heeringen): 384-404. Wiley, 2000.

2 Foster T, Gillespie K, McClelland R. Mental disorders and suicide in Northern Ireland. Br J Psychiatry 1997; 170: 447-52.

3 Hawton K, Zahl D, Weatherall R. Suicide following deliberate self-harm: long-term follow-up of patients who presented to a general hospital. Br J Psychiatry 2003; 182: 537-42.

4 Nordentoft M, Breum L, Munck LK, Nordestgaard AG, Hunding A, Laursen Bjaeldager PA. High mortality by natural and unnatural causes: a 10 year follow up study of patients admitted to a poisoning treatment centre after suicide attempts. BMJ 1993; 306: 1637-41.
5 Suokas J, Lonnqvist J. Outcome of attempted suicide and psychiatric consultation: risk factors and suicide mortality during a five-year follow-up. Acta Psychiatr Scand 1991; 84: 545-9.

6 Owens D, Horrocks J, House A. Fatal and non-fatal repetition of self-harm. Systematic review. Br J Psychiatry 2002; 181: 193-9.

7 Jenkins GR, Hale R, Papanastassiou M, Crawford MJ, Tyrer P. Suicide rate 22 years after parasuicide: cohort study. BMJ 2002; 325: 1155.

8 Greer S, Bagley C. Effect of psychiatric intervention in attempted suicide: a controlled study. BMJ 1971; 1: 310-2.

9 Cooper J, Kapur N, Webb R, Lawlor M, Guthrie E, Mackway-Jones K, et al. Suicide after deliberate self-harm: a 4-year cohort study. Am J Psychiatry 2005; 162: 297-303.

10 Beautrais AL. Subsequent mortality in medically serious suicide attempts: a 5 year follow-up. Aust N Z J Psychiatry 2003; 37: 595-9.

11 Skogman $K$, Alsen $M$, Ojehagen A. Sex differences in risk factors for suicide after attempted suicide-a follow-up study of 1052 suicide attempters. Soc Psychiatry Psychiatr Epidemiol 2004; 39: 113-20.

12 Suominen K, Isometsa E, Haukka J, Lonnqvist J. Substance use and male gender as risk factors for deaths and suicide-a 5-year follow-up study after deliberate self-harm. Soc Psychiatry Psychiatr Epidemiol 2004; 39: 720-4.

13 Chen VCH, Tan HKL, Cheng ATA, Chen CY, Liao LR, Stewart R, et al. Non-fatal repetition of self-harm: population-based prospective cohort study in Taiwan. Br J Psychiatry 2010; 196: 31-5.

14 Chen VC, Cheng AT, Tan HK, Chen CY, Chen TH, Stewart R, et al. A community-based study of case fatality proportion among those who carry out suicide acts. Soc Psychiatry Psychiatr Epidemiol 2009; 44: 1005-11.

15 NHS Centre for Reviews and Dissemination. Effective Health Care Bulletin: deliberate self-harm. Effective Health Care 1998; 4: 1-12.

16 Hawton K, Townsend E, Arensman E, Gunnell D, Hazell P, House A, et al. Psychosocial versus pharmacological treatments for deliberate self harm. Cochrane Database Syst Rev 2000; 2: CD001764.

17 Cheng AT. Mental illness and suicide. A case-control study in east Taiwan Arch Gen Psychiatry 1995; 52: 594-603.

18 Owens D, Wood C, Greenwood DC, Hughes T, Dennis M. Mortality and suicide after non-fatal self-poisoning: 16-year outcome study. Br J Psychiatry 2005; 187: 470-5.

19 Suominen K, Isometsa E, Suokas J, Haukka J, Achte K, Lonnqvist J. Completed suicide after a suicide attempt: a 37-year follow-up study. Am J Psychiatry 2004; 161: 562-3

20 Carter G, Reith DM, Whyte IM, McPherson M. Non-suicidal deaths following hospital-treated self-poisoning. Aust N Z J Psychiatry 2005; 39: 101-7.

21 Gibb SJ, Beautrais AL, Fergusson DM. Mortality and further suicidal behaviour after an index suicide attempt: a 10-year study. Aust N Z J Psychiatry 2005; 39: 95-100.

22 Mohler B, Earls F. Trends in adolescent suicide: misclassification bias? Am J Public Health 2001; 91: 150-3.

23 Skegg K. Self-harm. Lancet 2005; 366: 1471-83.

24 Prince M, Patel V, Saxena S, Maj M, Maselko J, Phillips MR, et al. No health without mental health. Lancet 2007; 370: 859-77.

25 Hemingway $\mathrm{H}$, Marmot $\mathrm{M}$. Evidence based cardiology: psychosocial factors in the aetiology and prognosis of coronary heart disease. Systematic review of prospective cohort studies. BMJ 1999; 318: 1460-7.

26 Golden $\mathrm{SH}$, Williams JE, Ford DE, Yeh HC, Paton Sanford C, Nieto FJ, et al. Depressive symptoms and the risk of type 2 diabetes: the Atherosclerosis Risk in Communities study. Diabetes Care 2004; 27: 429-35.

27 Blazer DG, Hybels CF, Pieper CF. The association of depression and mortality in elderly persons: a case for multiple, independent pathways. J Gerontol $A$ Biol Sci Med Sci 2001; 56: 505-9.

28 Nordstrom P, Samuelsson M, Asberg M. Survival analysis of suicide risk after attempted suicide. Acta Psychiatr Scand 1995; 91: 336-40.

29 Suokas J, Suominen K, Isometsa E, Ostamo A, Lonnqvist J. Long-term risk factors for suicide mortality after attempted suicide-findings of a 14-year follow-up study. Acta Psychiatr Scand 2001; 104: 117-21. 